\title{
La prensa afroporteña y el pensamiento afroargentino a finales del siglo XIX
}

\author{
Jean-Arsène YAO \\ Universidad Félix Houphouët-Boigny \\ jeanarsene.yao@yahoo.es \\ jean.yao@univ-fhb.edu.ci
}

Recibido: 3 de febrero de 2015

Aceptado: 18 de junio de 2015

\section{Resumen}

El auge periodístico que se produjo en Argentina a partir de la segunda mitad del siglo XIX vio la aparición de una activa prensa afroporteña defensora de los intereses de la comunidad negra. Este trabajo, además de repasar la historia de los periódicos afroargentinos, subraya el papel desarrollado por la élite de ascendencia africana en la promoción de la modernidad entre los suyos, a la vez que explora las posibles bases para una identidad propia en las ideas que diseminaron.

Palabras clave: afroporteño; periódicos; política; integración; progreso.

\section{The Afroporteña press and Afro-Argentine's thought in the late nineteenth century}

\begin{abstract}
The journalistic boom that occurred in Argentina from the second half of the nineteenth century saw the emergence of an active afroporteña press that defend the interests of the black community. This paper, in addition to reviewing the history of the Afro-Argentines newspapers, emphasizes the role played by the elite of African descent in the promotion of modernity among his brothers, while exploring the possible bases for an identity in the ideas spread.
\end{abstract}

Key words: afroporteños; newspapers; politics; integration; progress.

\section{Referencia normalizada:}

Yao, J. A. (2015). La prensa afroporteña y el pensamiento afroargentino a finales del siglo XIX. Historia y Comunicación Social. Vol 20, número 1 (enero-junio), páginas 137-157.

Sumario: 1. Introducción. 2. Construcción intelectual de la argentinidad. 3. El derecho de ser y existir. 4. Promotores de la causa negra. 5. Culto de la modernidad. 6. Discurso y práctica política. 7. Conclusión. 8. Fuentes. 9. Referencias bibliográficas. 


\section{Introducción}

Dentro de las múltiples dinámicas que se derivaron de la consecución definitiva de la independencia de las naciones latinoamericanas, el ejercicio de construir conceptos, clasificar grupos humanos y representar los territorios fue, sin duda, uno de los procesos más complejos al que tuvieron que enfrentarse todos los sectores que se dieron a la difícil tarea de dirigir las nacientes repúblicas (Flórez, 2010: 530).

En Argentina, la necesidad de crear un Nosotros colectivo llevó a la élite a difundir pautas culturales, mitos de origen y un conjunto de símbolos tendentes a la consolidación de una identidad nacional, cuya base conceptual se asentaba en la obra de próceres como Bartolomé Mitre, Domingo Faustino Sarmiento, Juan Bautista Alberdi, Esteban Echeverría. Este último declaraba que "En América todo lo que no es europeo, es bárbaro; no hay más división que ésta: primero el indígena, es decir el salvaje; segundo, el europeo, es decir nosotros" (1852: 49-56).

Para borrar esta barbarie, promovieron la inmigración europea que permitiría forjar a ciudadanos blanqueados en color, y europeizados en mentalidad y costumbres. Consecuencia de lo cual, el reclamo de una argentinidad sin indios ni negros -a los que Sarmiento tilda de "raza salvaje" (1845 [1990]: 233)-, expresión de una construcción ideológica que ha hecho del estereotipo nación de raza blanca y de cultura europea un elemento clave de la identidad argentina (Quijada, 1994: 15-21).

De esta forma, el racismo se inscribió como un mecanismo estatal, no necesariamente a través de una legislación escrita o del sistema económico, pero sí a través de las operaciones ideológicas eurocentristas agenciadas y estimuladas por el Estado moderno (Ocoró, 2010: 60). Fue así porque, para usar el término de Benedict Anderson (1993), las naciones se imaginan "desde arriba".

Sin embargo, no sería aventurado afirmar que este proceso de negación del Otro, en nuestro caso de la negritud, a pesar de haber sido impuesto, también contó con la oposición y/o complicidad de los propios afroargentinos. De hecho, mientras se llevaba a cabo el "genocidio discursivo" Solomianski (2003), es decir, la omisión de cualquier reconocimiento racial que no fuera del blanco, en Buenos Aires, los afrodescendientes plasmaban sus argumentos -algunos favorables al blanqueo-, discusiones y críticas en los periódicos que poseía.

Hubo por lo menos media docena de periódicos cuya edición se atribuye a la comunidad negra, siendo los más famosos El Artesano, La Broma, La Igualdad, La Juventud, El Proletario, La Raza Africana, El Tambor y El Unionista. Un periodismo afroargentino muy prolífico cuya importancia fue más allá de esta comunidad, como así lo demuestra la multiplicación de los avisos publicitarios y dirigidos a la colectividad inmigrante, especialmente a los italianos ${ }^{1}$.

Además de los temas políticos y económicos, se encontraban también análisis de la situación de los negros una vez abolida la esclavitud, chistes, poemas y relatos. Estos periódicos compartían con el resto de medios, cuestiones, polémicas e intereses, pero 
también ponían en evidencia la singularidad de problemas, sobre todo la persistencia de prejuicios raciales, que atravesaban los afroargentinos ${ }^{2}$.

Si bien dentro del conjunto de investigaciones sobre la afrodescendencia en Argentina, se ha destacado, con mayor o menor rigor, el gran valor documental de la prensa producida por los negros porteños en el ocaso del siglo $\mathrm{XIX}^{3}$, la relevancia de este estudio reside en la lectura crítica enmarcada en el constructivismo social (Gellner, 1988; Hobsbawm, 1990; Anderson, 1993) que se hace de estos periódicos.

Así pues este trabajo se propone explorar y rescatar los debates, las experiencias y la tentativa de subvertir el orden hegemónico, tanto político-económico como cultural, por parte de los afroargentinos a través de la prensa que producían. Percibiendo estos periódicos como formas de construcción de una identidad étnica, enfatizaré también en su papel en el adoctrinamiento del colectivo afrodescendiente y en la difusión de ideas de modernidad en su seno. Prueba de su aceptación del blanqueo como mecanismo no solo de ascensión social sino también de participación política.

\section{Construcción intelectual de la argentinidad}

Para lograr nuestros objetivos, consideramos necesario tener en cuenta un factor contextual que sin duda los condicionó el discurso periodístico de los afroargentinos. Se trata de la narrativa dominante de la nación que, al contrario de las vigentes en otros países latinoamericanos, no glorifica el mestizaje (Martínez Echazábal, 1998), sino la blanquedad (Frigerio, 2008: 118).

En efecto, está muy arraigada en el sentido común argentino la idea según la cual la población de ascendencia africana desapareció, atribuyendo la misma, en general, a la supuesta muerte en gran escala debido a diversas epidemias ocurridas a lo largo del siglo XIX y su participación en las guerras de independencia. Este supuesto también se basa en el proceso de mestizaje entre los afroargentinos y los inmigrantes europeos que arribaron a finales de la misma centuria.

Sin embargo, la presunta desaparición de los afroargentinos debe entenderse también como fruto de un proceso de invizibilización generado por el Estado (Andrews, 1989). Dicha operación,

fue reafirmada por la desaparición de los registros oficiales relativos a la población de ascendencia africana a través de la utilización del rótulo de 'población desconocida', que subestimaba el número de afroargentinos al contemplar personas negras sin especificar el color o también en el uso de la categoría 'trigueño' que no implica una directa ascendencia africana (López, 2006:7).

En aquel entonces, los espejismos de igualdad socioracial congelaron temporalmente las expresiones de etnicidad. Los antiguos esclavos y sus descendientes fueron considerados ante la ley en igualdad de condiciones que el blanco y el indio. Al mismo tiempo, la élite hacía suyos los conceptos y valores raciales sosteniendo que 
el ancestro europeo era el bien más valioso que podía poseer una persona. Se enorgullecieron de haber conservado su sangre blanca totalmente pura o con poca mezcla de sangre africana.

Las peculiares características que adoptó la construcción de la identidad nacional se relacionan intrínsecamente también con la problemática desatada a partir de la sanción, en 1880, de la Ley Nacional de Inmigración. Como es sabido, el espíritu que animaba esta normativa era atraer a los habitantes de las naciones "más avanzadas" de Europa para distribuirlos prolijamente por la vastedad del suelo argentino (Prieto, 1988: 16 y ss.). Se fomentó el mito de la Argentina blanca, mito que presenta como antecedente y base ideológica la obra de Domingo Fausto Sarmiento y Juan Bautista Alberdi. Ambos autores tenían un pensamiento profundamente eurocéntrico. Alberdi sostenía que los argentinos eran europeos adaptados a vivir en América. Más, afirmó:

En América todo lo que no es europeo, es bárbaro; no hay más división que ésta: primero el indígena, es decir el salvaje; segundo, el europeo, es decir nosotros (Alberdi, 1852: 49-56).

¿Y el negro? Aparece una voluntad de ocultar este componente de la sociedad americana que existía desde los primeros momentos del descubrimiento y conquista del Nuevo Mundo. Se presentó la urgencia de proponer el exterminio del indígena y el ocultamiento del negro, como representantes de la barbarie que componían parte de la realidad argentina:

Crucemos con ella -la inmigración de origen británico- nuestro pueblo oriental y poético de origen y le daremos la aptitud del progreso y de la libertad práctica (Alberdi, 1852: 110).

Este concepto de "exclusión por fusión" llevaría a un decrecimiento demográfico de la población negra. Progresar era salir de América para entrar en Europa y por tanto la insistencia de la negación del indio, el negro y el ansia por ser europeos. Esta pauta histórica provocó un método que luego se hizo norma. Se sustituyó a los afroargentinos por los inmigrantes europeos. Más aún, Alberdi consideraba que la inmigración era condición previa de la civilización:

Se hace este argumento: educando nuestras masas tendremos orden, teniendo orden, vendrá la población de fuera. Os diré que invertís el verdadero método de progreso. No tendréis orden, ni educación popular, sino por el influjo de masas introducidas con hábitos arraigados de ese orden y buena educación (Alberdi, 1852: 93).

El presidente Bartolomé Mitre tuvo el mismo pensamiento eurocéntrico. Para él, la inmigración era una evolución de la humanidad, un elemento de progreso, una evolución grandiosa que permitía robustecer la nacionalidad argentina para que templara y regenerara la raza blanca:

...que nuestros hijos y los hijos de los inmigrantes se identifiquen en un solo amor, para que nuestra raza se salve, para que nuestro estado social se mejore, para que nuestra nacionalidad no se debilite... (Mitre, 1870). 
Por su parte, Sarmiento creía que las ideas y el esclarecimiento no se aprendían sino que se heredaban genéticamente. Así, la instrucción sola no sería suficiente para sacar a Argentina de su "barbarie"; se requería una real infusión de genes blancos, representantes de la civilización, de lo urbano (Sarmiento, 1845). Barbarie era el resto y para conseguir el progreso, Argentina debía borrar o destruir lo bárbaro que había en su seno. Se trataba de ser o no salvaje, y para no ser salvaje era necesario civilizar. La intelectualidad argentina decimonónica estuvo también adscrita al positivismo revalorizando el espíritu naturalista. Exponía el método objetivo, experimental y positivo de la ciencia natural. Este auge intelectual coincidió con el gobierno de Julio Argentino Roca, que fue la expresión política del positivismo. La explosión de prosperidad económica convenció a muchos de la superioridad del positivismo. Se trató de encasillar todo lo humano y extra humano dentro de leyes positivas. Buscaron convertir la historia en una ciencia como la física, sujeta a inconmovibles postulados dentro de fórmulas de una precisión matemática.

Se fomentó una historiografía científica basada en conceptos modernos y eficientes. Toda especulación abstracta carecía de sentido, por lo que se debía prever todo. La historia se convertía de este modo en una rama de las ciencias naturales. José Ingenieros, tal vez el más influyente de todos los sociólogos argentinos tomando mucho del darwinismo social, afirmó que:

La historia no es un registro de la lucha de clases ni de la lucha institucional sino antes bien de la lucha racial. América latina es un claro ejemplo de este fenómeno ya que la raza blanca ha ocupado un área previamente dominada por miembros de una raza inferior (Ingenieros, 1913: 41-42).

Fue uno de los autores que abogaron por una adaptación de las teorías europeas a la realidad americana y al aniquilamiento de lo que llama "raza inferior". Es más, afirmó que el resultado inevitable de mezclar razas inferiores con otras razas superiores era una descendencia raquítica, simiesca, con todos los defectos de la raza noble acentuados por la sangre villana (Ingenieros, 1930: 35). Sostenía que las razas blancas y no blancas debían desarrollarse separadamente.

Así, los negros y los indios perderían de manera inevitable en la lucha para el predominio. Considerando a los afroargentinos como seres más próximos a los simios antropoides que a hombres civilizados, José Ingenieros sostuvo que todo lo que se hacía a favor de las razas inferiores era anticientífico. A lo sumo se los podría proteger para que se extinguieran agradablemente. En otra oportunidad afirmó que:

La europeización no es en nuestro concepto, un deseo...; es un hecho inevitable, que se produciría aunque todos los hispanoamericanos quisieran impedirlo. Nace de causas determinantes que ya existen ajenas a nuestro deseo. Por una ley sociológica inevitable los agregados sociales más evolucionados se sobreponen a los menos evolucionados... Nos europeizaremos oportunamente, como lo preveía Sarmiento la sociología puede afirmar esa futura transformación de la América latina (Morner, 1967: 141). 


\section{El derecho de ser y existir}

Lo que precede forma parte de las operaciones de ingeniería social necesarias para la construcción de una nacionalidad en las cuales es de vital importancia la creación de valores simbólicos que la sostengan. En tal sentido, la formación de la nación Argentina es un producto artificial de la historia del período, fruto de un proceso de construcción no sólo de las formas de organización política, sino también de la correspondiente identidad nacional (Chiaramonte, 1989: 92).

Al cultivar el mito de la sociedad blanca, la élite optó por borrar de la historia lo que representó la barbarie. Por lo tanto, la ausencia de los negros en los censos no puede ser argumentada sólo a través de criterios cuantitativos (Otero, 2006). Sin duda obedeció al deseo de las élites de configurar un componente población ideal a la nación imaginada, desalentando y combatiendo desde diversas estrategias a otros grupos.

Otero considera que hubo condicionantes ideológicos desplegados por la élites, entre los que señala las motivaciones igualitaristas de la estadística liberal que rechazaban las categorías producidas del orden colonial para no reproducir el oprobioso sistema de clasificación, pero que al mismo tiempo, mantenía las jerarquías de los distintos grupos sobre la base de criterios evolucionistas y no igualitarios.

La llegada masiva de inmigrante, consecuencia de la política "civilizadora", causó profundos cambios en Argentina. Esta oleada liberó al país de su prolongada y multifacética dependencia de la población afrodescendiente, haciendo hincapié en el fin del monopolio de la fuerza laboral negra. Frente a esta invasión, la reacción de los negros no se hizo esperar. Manifestando su rechazo hacia la política inmigratoria de los gobernantes, los negros no dudaron en utilizar todos los medios a su alcance, incluido el cante:

Napolitanos usurpadores, que todo oficio, quitan al pobre [...]. Ya no hay negros botelleros, ni tampoco changador, ni negro que venda fruta [...]"'(Andrews, 1989: 211).

A pesar de todo, no pudieron parar las grandes olas de inmigrantes dispuestos a trabajar largas horas a cambio de un bajo jornal, enviándolos así al olvido social. De ahí que el blanqueo se impuso como mecanismo no solo de ascensión social sino también de participación política. El problema político-teórico en el que los afroargentinos se centraron a partir de entonces, y que se reflejó en el cambio en la forma de autodefinición, fue el de la identidad. La comunidad afroargentina consideró necesaria la construcción de una "identidad minoritaria", ya que de este modo se abría la posibilidad de conformar una "minoría", y así reclamar derechos civiles según la tradición política del liberalismo.

Por esto merece especial atención saber que en ocasiones los negros fueron reacios ante el mestizaje. En efecto, la noticia de un futuro matrimonio entre una joven negra y un criollo "sacudía" a veces la comunidad afroargentina: 
Como es lógico, ellos creen que el hecho ofende la dignidad de la raza. Pero suelen ser filosofía [...] la raza va perdiendo en la mezcla su color primitivo. Se hace gris. Se disuelve. Se aclara. El árbol africano está dando blancas flores caucásicas (Soisa Reilly, 1905).

Esta actitud de la comunidad afroargentina parece derivar de la conciencia que tuvo en cuanto a la tendencia a ignorar o disminuir su presencia física. A la par que "el árbol africano" daba blancas flores, se abría la llaga de las muletillas según las cuales los afroargentinos habían desaparecido.

Pese a eso, en su búsqueda de reconocimiento social y definición política, algunos afroargentinos respondieron con voluntad ante esta oportunidad de escapar de su condición de casta que habían soportado por generaciones. Se alejaron de su pasado negro y africano adoptando la cultura y los refinamientos europeos favorecidos por la sociedad blanca. Su actitud se puede interpretar desde el constructivismo que relativiza los intentos de conformar una única cultura, al considerar que toda identidad es relativa a un contexto socio-histórico específico (Foucault, 1985). Contrariamente al esencialismo que sostiene una noción de identidad ahistórica e invariable.

Al mismo tiempo que permitía ampliar su posibilidad de participación en la vida económica y social, la modernización del país propició la ascensión social de un pequeño sector de familias afroargentinas de las cuales saldrían intelectuales que incluso llegarían a ocupar cargos electivos. Uno de ellos fue el diputado provincial Rosendo Mendizábal, elegido en 1853. Sin duda este acontecimiento contribuyó a una más activa participación política de los negros. Tres años después, el coronel negro Domingo Sosa fue elegido diputado en 1856 para la legislatura de la Provincia de Buenos Aires (Rodríguez Molas, 1961: 119).

Pero hubo que esperar el ocaso del siglo XIX para que los afroargentinos tuvieran una presencia significativa en la vida política. Colaboraron con la Unión Cívica Radical, como fue el caso del escribano Tomás Braulio Platero (Platero, 1980: 13) o del payador Gabino Ezeiza. Hecho realmente importante para la élite afroargentina fue la interpretación Radical de la historia argentina. Según el esquema liberal los unitarios ${ }^{4}$ equivalían a la civilización, mientras los federales ${ }^{5}$ eran la barbarie.

Aunque el radicalismo no ofreció variantes, se separó de la versión clásica Liberal en cuanto al gobierno de Rosas y los caudillos. Asumió una posición comprensiva y objetiva, justificando la historia deslindando los aspectos más duros del gobierno del dictador. El radicalismo abrigaba un nacionalismo hondamente popular (Scenna, 1976: 86 y siguientes). De allí que el radicalismo ofrecía a la élite afroargentina la doble oportunidad de dejar de avergonzarse por el apoyo cultural que Rosas dio a la comunidad negra ${ }^{6} \mathrm{y}$ reivindicar el servicio de sus padres que militaron en las filas unitarias? 


\section{Promotores de la causa negra}

Así las cosas, en la segunda mitad del siglo XIX, y siguiendo una tendencia que afectaba a los países europeos y americanos, Argentina se vio inmersa en una corriente ascendente de profusión de publicaciones escritas, en la que los periódicos fueron protagonistas (Geler, 2008: 199-226). Leer o sostener periódicos se transformaron en maneras fundamentales de participación en la vida social, permitiendo la creación de una imaginación nacional (Anderson, 1993) al involucrar a los lectores en los eventos de su país - o del país al que hacía poco se había arribado- fomentando la intervención y la opinión individual y colectiva (Sábato, 1998).

Dentro de este proceso se puede apreciar el desarrollo de una prensa de carácter popular (González, 2001), parte importante de la cual era publicada por y para la población afrodescendiente de Buenos Aires. También hacer periodismo requería un nivel mínimo de formación que no tenía la mayoría de los afroargentinos en aquella época. De allí que solo unos pocos - que conformaban la élite- pudieron lanzarse al periodismo. Entre otros miembros de las comisiones directivas de los periódicos se puede citar a Horacio Mendizábal, Santiago Elejalde, Ida Edelvira Rodríguez, Gervasio Méndez, Froilán P. Bello, Juan A. Costa, Dionisio Malo, José M. García, Valerio J. Bello, G. M. Arrieta, Juan Balparda, Benjamín Ramos y Gabino Ezeiza.

Sus textos ocupaban generalmente el espacio privilegiado de la primera nota, después se entregaban diversas secciones que iban desde relatos humorísticos, folletines, comunicaciones o informaciones acerca de sociedades carnavalescas, poesías, variedades y otros rubros. Los periódicos afroargentinos eran mucho más órganos de opinión, variedad, entretenimiento e incluso comunicaciones particulares entre lectores que de información de "noticias".

En este sentido cohesionaban a sus lectores en tanto comunidad y brindaban un espacio para el intercambio de ideas. Por otro lado, esta cohesión implicaba un cierto nivel de distanciamiento con los adherentes a otro periódico rival. Si bien a veces estas lealtades llevaban a enfrentamientos subidos de tono, se puede decir que estos mismos enfrentamientos provocaban la comunicación entre los diversos grupos afroargentinos. Asimismo, favorecían el ejercicio de una conciencia crítica por parte de actores sociales generalmente rechazados en los ámbitos específicamente intelectuales de la cultura dominante. Eso se resume en La Raza Africana:

Nuestra bandera es de paz e igualdad; nuestros principios y nuestras convicciones son las mismas que obligaron a nuestros mayores a hacer la gran cruzada en 1810 , dando por resultado, haber roto la férrea cadena, con que el coloso sujetaba al esclavo, y una vez rota, gozó de libertad todo el continente sur americano ( 7 de enero de 1858).

Los periódicos afroargentinos buscaron un reconocimiento social de la población de origen africano. Se refirieron claramente a la situación racial de la colectividad negra. El Proletario lo expresaba en su prospecto: 
El gremio de color del Estado de Buenos Aires quiere salir de la nulidad en que yace, y abrirse un porvenir honroso y feliz, preciso es que se convenza de la necesidad absoluta que tiene de tener un periódico dedicado a solo el objetivo de ilustrarlo en sus intereses y cuestiones... (16 de junio de 1858).

Una de sus herramientas privilegiadas fue la denominada "política de la visibilidad", es decir, un conjunto de estrategias de crítica y creación de patrones sociales de representación, interpretación y comunicación (Fraser, 1997). Si bien en sus escritos defendían las ideas de modernidad impuestas por la clase dominante blanca, reconocían sin embargo la existencia de rasgos mínimos comunes que derivaban de la situación diferencial dentro de la cultura general.

En consecuencia, los artistas e intelectuales afroporteños se abocaron así a la construcción de un espacio simbólico en donde el tema de la identidad fue el protagonista. Ante la necesidad de diferenciarse del aluvión inmigratorio, las élites negras y mulatas argentinas realizaron el previsible recurso a la cultura. Como medios de comunicación estos periódicos emitían, a través de sus editoriales, sus enfoques acerca de diversos temas de actualidad desde una perspectiva de clase o de raza.

Pero siempre desde una posición de valentía en abierto enfrentamiento con los poderes públicos. En un editorial titulado "Negros y Blancos", El Unionista expresó claramente las intenciones de aquellos morenos y la ideología del periodista negro:

Los hombres todos son iguales y solo se distinguen como hemos dicho por su mayor inteligencia o por su dinero, pero en ningún caso por su color ( 9 de diciembre de 1877).

Sabido es que las premisas centrales en torno a la subalternidad de determinados grupos de personas son aquellas relacionadas con los estereotipos culturales, las opresiones de clase y de etnia (Raspisardi y Bellucci, 2001: 196). Por esto mismo, quienes escribían en los periódicos afroporteños centraron su atención en el rol opresor de las instituciones tradicionales públicas y privadas, la falta de igualdad de oportunidades en el campo laboral y las modificaciones al orden jurídico.

Es lo que se aprecia en la prensa afrodescendiente, en la que los "subalternados" no solo expresaban un punto de vista opuesto al oligárquico en función de la historia y el orden social en general sino que intervenían, con una voz valiente y animada, en situaciones particulares. Aportaron incluso un lúcido y progresista proyecto de democratización del país como se pudo ver en las líneas de La Juventud que realizó una labor comunicacional notablemente similar:

Banderas al viento: la idea de la libertad es la que por segunda vez va a hacernos ocupar un modesto puesto en la prensa periódica de nuestra sociedad. (...) con estos sanos propósitos, hemos de luchar hasta el último instante que tengamos de vida con tal de obtener una verdadera fórmula política y social (3 de marzo de 1878).

En un número correspondiente a la rememoración de la fecha de la Independencia, este periódico no dejó de hacer una problemática enunciación celebrativa: "Somos argentinos y pertenecemos a una clase desheredada de todos los derechos y prerro- 
gativas que acuerda nuestra Carta Fundacional, pero no por eso dejaremos de amar, servir y cooperar al florecimiento y prosperidad de la que se llama patria" (La Juventud, 10 de julio de 1878). En el repertorio de ideas y expresiones de los periódicos afroargentinos, uno de los temas más recurrente era el de la organización de la clase proletaria.

Asimismo, resultaba sorprendente la virulencia de algunos fragmentos que, a veces sin decirlo explícitamente, realizaban ataques o críticas a miembros destacados de la vida sociocultural argentina:

La huelga tipográfica: el lunes por la mañana se declararon en grève casi todos los operarios de las imprentas de esta ciudad. Hacía tiempo que el tipógrafo vivía en la más espantosa y bajo la más severa y terrible tiranía. No era el operario que se retribuía como se merece. No, era una máquina automática que servia para labrar la fortuna de algunos que se dicen defensores del pueblo y que ostentan al frente de sus hojas el nombre de los que viven del sudor de operario. (...) siendo La Broma órgano de las clases proletarias, les envía palabras de aliento y desea que las ideas socialistas cundan no solo entre los tipógrafos sino entre todas las clases obreras (La Broma, 5 de septiembre de 1878).

Cuando reclamaban con razón la transparencia de la vida política, lo reclamaban también para ellos mismos. Cuando exigían el derecho a juzgar a los demás, lo exigían incluso para ellos mismos. Los periodistas afroargentinos eran conscientes de que el derecho a la polémica no era único, que los defensores de la verdad, de la honradez y de la virtud obligatoriamente no eran de un lado y nunca del otro. La Broma ilustró lo anterior así:

Entre nosotros no se disipa ni se disipará jamás el amor patrio, el sentimiento nacional. El hombre de color ha contribuido con su sangre desde la guerra de nuestra independencia (23 de septiembre de 1879).

Asimismo, se perfiló como una luchadora por las libertades que alzaba la voz cuando detectaba cualquier injusticia hacia la comunidad negra:

¡Sí! Porque esa libertad de que gozan los que hoy nos escarnecen no se la deben a ellos mismos sino a lo sacrificios heroicos y abnegados de esa raza indomable. (...)¡Qué triste premio se ha dado a esa raza! ¡Hasta donde llega el orgullo humano! ¡Ingrato! Vosotros, blancos, aristócratas de cajón que tanto blasonáis de libres e independientes decid, ¿a quien debéis vuestras libertades y vuestra independencia? ¿A vosotros mismos? ¡No! (La Broma, 20 de noviembre de 1879).

Esta actitud otorgó a la prensa afroargentina una responsabilidad que fue más allá de su función informativa. Es más, desempeñó un objetivo social comunitario, de informar y de denunciar cualquier tendencia restrictiva:

Los hombres encargados de hacer respetar y cumplir la constitución son los primeros en violarla. Empezando por excluirnos de todo derecho a aspirar a cualquier puesto político. (...) la igualdad en nuestra patria solo existe en la forma ( $\mathrm{La}$ Broma, 18 de diciembre de 1879). 
Es interesante señalar que a partir del 14 de marzo de 1880 La Broma adjunta a su nombre, como lema o como parte de este, la caracterización "órgano de las clases obreras", haciéndose eco de la precaria situación de los trabajadores afros:

Nuestra misión: las artes y la industria traen consigo la riqueza del país, y nuestro pueblo que por sí solo es rico, cuanto no lo será el día que las artes, la industria y la agricultura estén en todo su apogeo, y podamos exportar en grandes cantidades los productos de nuestras fábricas. (...) el hacer de nuestros hermanos excelentes obreros es cuestión de vida o muerte (La Broma, 27 de enero de 1881).

En otra ocasión se refirió, en unos términos no menos virulentos, a una ley adoptada por las autoridades locales que afectaba a las trabajadoras y los trabajadores de los servicios domésticos:

La ley del embudo: 'ordenanza sobre el servicio doméstico' emitida por la Municipalidad de la capital. El espíritu que encierra es antagónico y su tendencia autocrática, nos recuerda la época del feudalismo. Debieran tratar de mejorarla estableciendo otras reglas que no sean las del absurdo ni las de la vil esclavitud" (La Broma, 19 de septiembre de 1881).

Los redactores de La Broma quisieron ir más allá de la interpretación periodística de lo momentáneo. Por eso su periódico sirvió como foro para la presentación de casi todos los puntos de vista sostenidos por los miembros de la comunidad. Querían levantar la sociedad negra:

Dejando una huella de bienes imperecederos en el espacio de la vida, difícil de borrar por las ambiciones y pretensiones de los hombres, porque eran las verdaderas crónicas y las fuentes fieles donde las generaciones venideras beberían la legitimidad $\mathrm{y}$ verosimilitud de nuestros hechos, nuestras ideas y nuestras fervientes aspiraciones (La Broma, 23 de diciembre de 1881).

\section{Culto de la modernidad}

Como ya comentamos anteriormente, algunos afroargentinos renegaron de su pasado con el objetivo de ser socialmente aceptados. Pues bien, se advierte en no pocos artículos un campo de fuerza en tensión entre ciertas maneras de hacer y de pensar respecto a qué consideraban bueno y necesario para su bienestar como individuos y como grupo social.

En estos momentos trabajamos activamente en el sentido de fundar un gran centro social sobre la base sólida de la unión, y cuyo objeto principal será el de difundir la ilustración en el seno de nuestra comunidad (La Juventud, 10 de enero de 1879).

Pablo Cirio denomina a esta tensión "tradición versus modernidad" (Cirio, 2009: 67). Si se tiene en cuenta el contexto del país en que transitaban, es comprensible que el marco de ebullición del ideario de la Generación del $80^{8}$, que estaba sentando las 
bases de la moderna nación argentina, los subsumiera en su misma dirección so pena de quedar al margen de una realidad que los trascendía.

Descartando cualquier juicio valorativo, los afroporteños se encontraban ante una encrucijada identitaria. Por un lado, gozaban de las mismas libertades cívicas que los blancos, como el derecho a voto en los hombres, pero buscaban cicatrizar las heridas de la época de Rosas (González, 2008: 216-217) con un manto de olvido (Solomianski, 2003: 104). Por otro lado, la búsqueda de educación, ilustración, trabajo e igualdad entre blancos y negros, y entre la mujer negra y el hombre negro era una meta anhelada pero, de hecho, en carrera a los mismos no pudieron partir del mismo lugar que los blancos.

Pues la hegemonía contaba con un arma de oro para demostrar su superioridad en todos los órdenes, el concepto de raza, gracias a los avances del racismo científico y el darwinismo social (Terán, 2008). De ese concepto la sociedad blanca hizo uso y abuso para inculcar las naturales desigualdades de los negros en cuestiones tan diversas como la higiene, los modales y la disciplina laboral. Con todo, ni siquiera fue una propuesta original del grupo dominante argentino, pues en la misma época todos los gobiernos americanos se alzaban deliberadamente con esas ideas irrebatibles a los efectos de perpetuarse en el poder y reservarse la riqueza (Annino y Guerra, 2003).

A los negros tales problemas les generaban o un confinamiento mayor en su esencialidad irremediablemente diferente o la necesidad de una integración a cualquier costo (Andrews, 2007). En la prensa estudiada, prueba de esto último es que las ideas socialistas que abrazaban con fervor ya desde 1858 los invitaban a subsumir sus especificidades culturales en rótulos trasnacionales y desetnizados como "obreros", "clases menos acomodadas" y "artesanos", por lo que la desestimación de sus tradiciones ancestrales era aún mayor.

En este marco, tradición versus modernidad se yergue como una antítesis de sentido donde los valores anhelados claramente se ubicaban en la modernidad. La Broma lo marca taxativamente cuando expresa tomar la bandera de la educación como "nuestra misión" (La Broma, 27 de enero de 1881), o al declarar que "Este órgano desde que se fundó, su objeto primordial fue, impulsar a nuestros hermanos a trabajar por el adelanto moral y material de nuestra comunidad" (La Broma, 3 de junio de 1882). Esta dicotomía aflora reiteradamente, a veces de modo sutil e incluso inconsciente. Veamos algunos ejemplos.

En el artículo "Sobre el mismo tema" (La Broma, 9 de marzo de 1882) se comenta que fue bien recibido el editorial del número anterior respecto al perfeccionamiento en música que deben tener los jóvenes de las sociedades carnavalescas. Una de estas, femenina, comenzará a instruirlos en flauta y violín, y así "demostremos la diferencia que hay entre una sociedad candombera que causa la hilaridad de todos y una sociedad musical que recibe siempre el aplauso general".

Aunque en esta diferenciación entre una música de estirpe tradicional-ancestral que mueve a risa respecto a otra, moderna y con instrumentos europeos que recibe el 
aplauso de todos, los negros parecían cerrar filas a favor de la segunda, hay artículos donde los contrasentidos valorativos son notorios. No obstante, si las disputas en torno a esta cuestión eran tan encendidas, ello se debía a que la práctica de su música tradicional, al menos durante carnaval, tenía consenso. Aunque no pueda saberse la razón de Carmen Saenz Valiente al publicar este pensamiento:

Allá en Europa, emperatriz de Occidente y señora de las demás naciones; allá centro del inmenso poder; es donde lograré conquistas (La Juventud, 30 de abril de 1878).

Es dable inferir que fue tramado en este contexto que posicionaba a Europa y la cultura blanca como promocional. En "Nuestras sociedades carnavalescas" ( $L a$ Broma, 3 de marzo de 1882), aparecen opiniones cruzadas sobre la música tradicional o ancestral negra y que pueden reducirse a cuatro ideas principales: Como una genuina práctica ancestral que en nada contradice a la tendencia mayoritaria; como bárbaras y vergonzantes costumbres que es conveniente olvidar en pos de un "progreso blanco"; como cálido recuerdo del "tiempo de los abuelos" que, si bien no interesa revivir, se guarda en la memoria; y como exaltación de lo afro".

El artículo refleja las discrepancias etarias respecto a lo que les sucedía y permite apreciar cómo los negros no podían cerrar filas respecto a la cuestión musical porque esta constituía un importante punto de inflexión en su modo de vivir y de (re)presentarse en la sociedad mayor. Sobre este campo de tensión en el contexto del carnaval, Geler (2008: 273) distingue entre las comparsas candomberas y las sociedades musicales, y realiza una aguda interpretación:

Ni La Broma ni La Juventud -ni La Perla- creían que las comparsas candomberas fueran beneficiosas para su comunidad, lo que quita que disfrutaran con ellas, y esto no fue producto de un viraje de posiciones. Estas sociedades ponían en escena una africanidad que los intelectuales subalternos rechazaban en el terreno público, ya que mostraban al resto de la sociedad tradiciones que no estaban ligadas a la modernidad, y que no eran admitidas ni siquiera en el contexto del carnaval, donde la permisividad y la burla de todos con todos por todo era supuestamente la regla [...] Las sociedades musicales, en cambio, evidenciaban el buen arte en el manejo de instrumentos y la habilidad compositiva de los afroporteños, su capacidad de organización y su acercamiento a los valores culturales que se imponían como aceptables.

\section{Discurso y práctica política}

El desarrollo de una época histórica implica, la intervención de varias generaciones, cada una de las cuales cumple una función determinada (Martínez, 1986: 203). En este sentido, los periódicos en la sociedad porteña decimonónica tienen una gran importancia que según Botana (2005: 21) deriva de

la garantía que la Constitución Nacional confería a la libertad de prensa, el diario escrito recogía información cotidiana y entraba de lleno en el juego político. Los 
diarios se confundían con las facciones, convocaban a los seguidores y enhebraban con ellos la trama asociativa de aquellos embrionarios partidos.

Dentro de este entramado se insertaba La Igualdad, El Artesano y El Tambor, que fueron subsidiados por partidos políticos que buscaban el apoyo de los negros para las elecciones presidenciales de 1868 (Andrews, 1990: 93). Los propagandistas mandaban mensajes a favor de uno u otro partido para conseguir el voto de los miembros de la comunidad.

Ambos periódicos fueron claros ejemplos de esta táctica de relaciones públicas. Manifiesta o sutilmente, todos tuvieron una incursión en la política partidaria, en aquellos sitios en donde era posible estar cercano al poder, matizando la independencia de la prensa afroargentina frente al poder político y económico. Fue el caso de Gabino Ezeiza quien siguió a Leandro Alem desde 1890 y puso su musa de payador al servicio de sus ideales cívicos.

Estuvo en la revolución de 1893 en Santa Fe (Pistone, 1999: 11), en el ataque de la aduana en la que se había acantonado una compañía del 3 de infantería y en las campañas políticas en las sierras de Córdoba, acompañado al líder de la Unión Cívica Radical, Hipólito Irigoyen (Soler Cañas, 1967: 69). Esta relación de complicidad entre el poder y la prensa afroargentina crecía o decrecía conforme las coyunturas que vivía el país y en la mayoría de los casos probó ser efectiva para inclinar la balanza o para dividir a la comunidad negra.

Una situación que denunciaron algunos periódicos a veces con una autoconciencia que se tornaba aún más llamativa cuando resultaba visualizable en tanto activismo comunicativo:

La Broma no vende su conciencia, La Broma no transija con caudillos políticos (...) sigamos; ¡sigamos! Qué nos importa que gobierne Juan Pedro o Diego, que mande quien mande, cuando aunque reconozcamos nuestros derechos y expongamos nuestra voluntad prestando nuestro voto y haciendo propaganda en los centros políticos, la resolución de un número de ciudadanos que se titulan padres de la patria es contradictoria muchas veces contra la verdadera voluntad de la mayoría del pueblo. (...) no nos inmiscuyamos en la corriente arrasadora de la política hasta tanto un candidato no haga en su programa un recuerdo especial de nuestra desheredada comunidad (La Broma, 11 de septiembre de 1879).

El voto de los afroargentinos era activamente buscado por los partidos políticos. Los periódicos La Igualdad, por segunda vez, y El Artesano tuvieron fuertes subsidios de los intereses políticos de Avellaneda y Mitre, respectivamente, para obtener el apoyo afroargentino en las elecciones presidenciales de 1874 (La Igualdad, 7 de julio de 1873). Parte de la prensa afroargentina estuvo por tanto ligada a intereses políticos que tuvieron precedencia sobre su objetividad informativa.

Si bien no se puede decir que éstos practicaron un periodismo faccioso y tendencioso, merece la pena señalar que su actitud distorsionó su misión y erosionó considerablemente su credibilidad. Y como se sabe, ningún periodista puede actuar con autonomía e independencia cuando combina su oficio con la política. De allí que el 
desdoblamiento de los periodistas provocó su divorcio de su papel como informador para adoptar una postura de publicista gratuito.

Los periódicos se convirtieron en canales por donde la objetividad de las informaciones fue supeditada indudablemente a los intereses de los políticos. Consecuencia: la política fue una de las principales fuentes de discordia. La campaña presidencial duramente luchada de 1874 resultó en un sentimiento particularmente malo. Las facciones rivales se enfrentaban con fuerza, y el conflicto finalmente culminó con una pelea a puñetazos en una elegante reunión social de afroargentinos (La Igualdad, 7 de junio de 1874).

Este escándalo permitió a La Broma quebrar lo que hasta entonces había sido la subordinación de parte de la prensa de afroargentina a los poderes políticos. Tratando de eliminar esta clase de disturbios de la vida de la comunidad, este periódico tomó posición contra la participación en toda agrupación o para todo candidato, sosteniendo que los políticos blancos habían empleado continuadamente a los negros en épocas de necesidad para luego olvidarlos cuando llegaba el momento de dividir el botín. Atacó a La Igualdad por haber servido como portavoz de los intereses de Avellaneda (La Broma, 20 de junio de 1879).

Los niveles de acercamiento de la prensa afroargentina hacia el poder llegaron al punto de polarizar de la comunidad negra: los seguidores de los partidos políticos por un lado, y los llamados apolíticos por el otro. Fue un hito fundamental en la historia de la prensa de afroargentina en su permanente lucha por los derechos de su comunidad. Es más, en 1879, La Broma anunció que no respaldaría a nadie en las siguientes elecciones porque estaba completamente desilusionado con todos los partidos. Instando a la comunidad a evitar las divisiones partidarias, el periódico proclamó:

Nuestro lema es unir no dividir, y con él estamos (La Broma, 20 de julio de 1879).

Los editores de La Juventud también encararon la cuestión de la política partidaria con franca e invariable crítica. Como La Broma, sostuvieron que la política solo servía para dividir a la comunidad negra y no producía ningún beneficio. Un artículo sobre los legisladores negros del periodo los describía como los trabajadores del partido que seguían servilmente los dictados de los líderes políticos (La Juventud, 30 de junio de 1878). Otro artículo posterior acusó a la prensa blanca de explotar a la comunidad de color con fines políticos. Decía que:

Los periódicos blancos solo informan acerca de nuestra comunidad cuando se organiza para apoyar a un candidato favorecido por los periódicos; cuando nos esforzamos para establecer una sociedad de ayuda mutua apolítica o un periódico apolítico, esos esfuerzos no reciben ningún comentario de parte de los principales periódicos. Así la prensa blanca alienta el conflicto y la discordia dentro de nuestra comunidad e ignoraba los esfuerzos por movilizarla por fines constructivos ( $\mathrm{La}$ Juventud, 10 de octubre de 1878).

Como es dable de imaginar, pese a su aparente independencia, existió una relación de complicidad entre parte de esta prensa y el poder. Tanto los dueños como quienes 
detentaban el poder sabían que el comportamiento del inmenso auditorio afroargentino podía ser manipulado o influido desde los periódicos, capaces de incentivar o apagar conflictos políticos, de encauzar tendencias, de crear imágenes dependiendo de los intereses que estuvieran en juego.

\section{Conclusión}

A modo de palabras finales, podemos decir que la prensa afroporteña representó un conjunto significativo en la consolidación del Estado nacional, con la tradición liberal como clave ideológica. En este contexto, consideramos que las narrativas producidas apuntaron a la ampliación del significado bajo el cual se ubicaba la población de origen africano, cuyas prácticas culturales y políticas persiguieron una ampliación de reconocimiento como comunidad.

En tanto espacios abiertos de discusión, estos periódicos fueron lugares de intercambio de información referente a la comunidad afroargentina, a la que quería representar pero que veía atrasada y dividida. De este modo, lucharon por llevar a cabo los cambios que consideraron necesarios desde una postura de portavoces y guías del colectivos afrodescendiente. Reflejaron esas luchas que formaban parte imprescindible de ellas, tomando la palabra para discutir y convencer de la idoneidad de sus ideas.

A nuestro parecer, las luchas manifestadas en estas publicaciones -entre La Broma y La Igualdad; El Artesano y La Igualdad- ponen de realce la celebración de las diferencias y una práctica deconstructiva del significado de su identidad. Por otra parte, debemos notar que la fragmentación hacia el interior de la comunidad afroporteña no solamente atendió a instancias culturales, sino que la condición de "clase" constituyó una línea divisoria con el resto de la sociedad argentina.

Aunque no es menos cierto que los medios de comunicación afroporteños contribuyeron a difundir entre los miembros de su comunidad los valores homogéneos impuestos por la clase dominante. Su objetivo era estandarizar criterios y acelerar su integración, transformándose en agentes de cambio o intelectuales subalternos. Siendo sus objetivos educar, ilustrar, pero también ordenar y disciplinar.

Por esto entedemos que supieron distinguir entre el uso político de la diferencia y la legitimidad de algunos reclamos particularistas. Su estrategia de privilegiar una narrativa de las diferencias puede entenderse como una práctica enmascaradora, ya que solo constituyó un alegato en favor de un consumo intracomunitario.

De hecho, los periódicos afroporteños hicieron suyas las ideas que circulaban en la Argentina decimonónica acerca del rol de la prensa escrita, de la tarea del periodista y de la importancia del progreso de los pueblos. Mostraron la importancia que estos conceptos tenían para la comunidad y la efectividad de las formas de acercamiento a 
los lectores de sus escritos. No fue una asimilación total y ciega del modelo estético hegemónico, ni tampoco un rechazo rotundo a este.

Esta situación, por tanto, les permitió construir una imagen de sí mismos, con un sentido particular, es decir, decidiendo qué pautas sociales aceptaban y reproducían y qué otras rechazaban. Así las cosas, los periódicos facilitaron la tarea del Estado en construcción de imponer su ideología y administrar a sus sujetos. Al actuar de este modo, reflejaban la idea constructivista según la cual las masas populares son las últimas en verse afectada por el surgimiento de la conciencia nacional.

Desde este punto de vista, es menester señalar que, aunque las motivaciones igualitarias del liberalismo político no derribaron totalmente las desigualdades étnicas raciales, sí permitieron que los afrodescendientes se pensaran como sujetos políticos y adelantaran reivindicaciones identitarias para sí mismos. En el caso de los periódicos analizados se manifiesta una fuerte auto-identificación étnica que funcionó como una forma de anclaje para aceptar y valorar sus propias costumbres y prácticas culturales.

En definitiva, dentro de la retórica identitaria expresada en los periódicos afroporteños existió una tensión discursiva entre narrativas de la diferencia y de la igualdad, en tanto, estas últimas promovían una desdiferenciación entre grupos, mientras que las primeras implicaban la afirmación de comunidades de valor, es decir, identidades específicas. Pero el recorrido crítico que hemos realizado nos permite concluir que esta tirantez se resolvió en oposición práctica.

\section{Fuentes}

El Artesano (1873). Biblioteca Nacional Argentina, Sala del Tesoro.

La Broma (1876-1882). Biblioteca Nacional Argentina, Sala del Tesoro.

La Igualdad (1873-1874). Biblioteca Nacional Argentina, Sala del Tesoro.

La Juventud (1876-1879). Biblioteca Nacional Argentina, Sala del Tesoro.

El Proletario (1858). Biblioteca Nacional Argentina, Sala del Tesoro.

La Raza Africana (1858). Biblioteca Nacional Argentina, Sala del Tesoro.

El Unionista (1976-1880). Biblioteca Nacional Argentina, Sala del Tesoro.

\section{Referencias bibliográficas}

ALBERDI, Juan Bautista (1852). Bases y puntos de partida para la organización política de la República Argentina. Buenos Aires: Museo Mitre.

ANDERSON, Benedict (1993). Comunidades imaginadas. Reflexiones sobre el origen y la difusión del nacionalismo. México: Fondo de Cultura Económica. 
ANDREWS, George Reid (2007). Afro-Latinoamérica 1800-2000. Madrid: Iberoamericana.

(1989). Los afroargentinos de Buenos Aires. Buenos Aires: Editorial de La Flor.

ANNINO, Antonio y Guerra, François (2003). Inventando la nación. Iberoamérica siglo XIX. México: Fondo de Cultura Económica.

BOTANA, Natalio (2005). El orden conservador. La política argentina entre 1880 y 1916. Buenos Aires: Debolsillo.

CHIARAMONTE, José Carlos (1989). "Formas de identidad política en el Río de la Plata luego de 1810". Boletín del Instituto de Historia Argentina y Americana "Dr. Emilio Ravignani", $3^{\mathrm{a}}$ serie, $\mathrm{n}^{\mathrm{0}} 1$, Buenos Aires.

CIRIO, Norberto Pablo (2009). Tinta negra en el gris del ayer. Los afroporteños a través de sus periódicos entre 1873 y 1882. Buenos Aires: Teseo.

DÍAZ, César Luis (2004). "Tras las huellas de un periodismo «desaparecido»". Oficios Terrestres, ${ }^{\circ} 15-16$, pp. 62-69.

FLÓREZ BOLÍVAR, Francisco Javier (2010). “HHijos de la barbarie o de la ciudadanía?: negros y mulatos en el marco del primer centenario de la independencia de Cartagena, 1911-1941". Mosquera, Claudia, et. al. (comp.), Debates sobre ciudadanía y políticas raciales en las Américas Negras. Colombia: Facultad de Ciencias Humanas, Universidad Nacional de Colombia, pp. 542 -570.

FOUCAULT, Michel (1985). Herculine Barbin llamada Alexine B. Madrid: Revolución.

FRASER, Nancy (1997). Iustitia Interrupta. Reflexiones críticas desde la posición postsocialista. Bogotá: Siglo del Hombre Editores - Uniandes.

FRIGERIO, Alejandro (2008). "De la desaparición de los negros a la reaparición de los afrodescendientes: comprendiendo las políticas de las identidades negras, las clasificaciones raciales y de su estudio en Argentina". Los estudios afroamericanos y africanos en América Latina: herencia, presencia y visiones del otro. Córdoba: CLACSO.

GELER, Lea (2010). Andares negros, caminos blancos. Afroporteños, Estado y nación Argentina a fines del siglo XIX. Rosario: Prohistoria.

(2008). "Guardianes del progreso. Los periódicos afroporteños entre 1973-1882". Anuario de Estudios Americanos, $\mathrm{n}^{\circ}$ 65, pp. 199-226.

(2007). "Aquí... se habla de política. La participación de los afroporteños en las elecciones presidenciales de 1874". Revista de Indias, n 240, pp. 459-484.

(2006). "La sociedad «de color» se pone de pie. Resistencia, visibilidad y esfera pública en la comunidad afrodescendiente de Buenos Aires, 1880". Dalla Corte, G.; GARCÍA JORDÁN, P., et al. (coords.), Homogeneidad, diferencia y exclusión en América Latina. Barcelona: Publicacions de la Universitat de Barcelona, pp. 141-153.

GELLNER, Ernst (1988). Naciones y Nacionalismo. Madrid: Alianza.

GONZÁLEZ BERNALDO de QUIRÓS, Pilar (2008). Civilidad y politica en los orígenes de la nación argentina. Las sociabilidades en Buenos Aires, 1829-1862. Buenos Aires: Fondo de Cultura Económica. 
HOBSBAWM, Eric (1990). Nations and Nationalism since 1780. Programme, myth, reality. Cambridge: Cambridge University Press.

INGENIEROS, José (1930). La locura en la Argentina. Buenos Aires: Cooperativa editorial.

(1913). Sociología Argentina. Madrid: Biblioteca científico-filosófica.

LÓPEZ, Laura Cecilia (2006). "De transnacionalización y censos. Los afrodescendientes en Argentina". Revista de Antropología Iberoamericano, vol. 1, $\mathrm{n}^{\circ}$ 2, pp. 265-286.

MARTÍNEZ de CODES, Rosa María (1986). El pensamiento argentino (1853-1910). Madrid: Editorial de la Universidad Complutense.

MARTÍNEZ ECHAZÁBAL, Lourdes (1998). "Mestizaje and the discourse of national/cultural identity in Latin America, 1845-1959". Latin American Perspectives, $\mathrm{n}^{\mathrm{o}} 25$ (3), pp. 21-42.

MITRE, Bartolomé (1870). Discurso sobre la inmigración espontánea en la República Argentina. Buenos Aires: Senado Nacional.

MORNER, Magnus (1967). Race mixture in the history of Latin America. Boston: Little Brown \& Company.

OCORÓ LOANGO, Anny (2010). "Los negros y negras en la Argentina: entre la barbarie, la exotización, la invisibilización y el racismo de Estado". La manzana de la discordia, vol. 5, no 2, pp. 45-63.

OTERO, Hernán (2006). Estadística y nación. Una historia conceptual del pensamiento censal de la Argentina moderna, 1869-1914. Buenos Aires: Prometeo.

PISTONE, Catalina J. (1999). "La presencia negra". Historia de Nuestra Región, pp. 11-16.

PLATERO, Tomás Antonio (1980). "Un escribano de color: Tomás B. Platero 18571925. Figura de la generación del 80 arquetipo de vida". Instituto de Historia del Notariado, $\mathrm{n}^{\mathrm{o}} 65$.

PRIETO, Adolfo (1988). El discurso criollista en la formación de la Argentina moderna. Buenos Aires: Sudamericana.

QUIJADA, Mónica (1994). "Sobre nación, pueblo, soberanía y otros ejes de la modernidad en el mundo hispánico". AHILA. Cuadernos de Historia Latinoamericana, $\mathrm{n}^{\mathrm{0}} 2$, pp. 19-51.

RAPISARDI, Flavio y Bellucci, Mabel (2001). "Identidad: diversidad y desigualdad en las luchas políticas del presente". Atilio Borón (comp), Teoría y filosofía política. La recuperación de los clásicos en el debate latinoamericano. Buenos Aires: CLACSO.

RODRÍGUEZ MOLAS, Ricardo (1961): "Negros libres rioplatenses". Revista de Humanidades, $\mathrm{n}^{\circ} 1$, pp. 99-126.

ROMEO, Cesar (2005). El carnaval de Buenos Aires (1770-1850): el bastión sitiado. Buenos Aires: Editorial de las Ciencias.

SÁBATO, Hilda (1998). La política en las calles. Entre el voto y la movilización, Buenos Aires, 1862-1880. Buenos Aires: Sudamericana.

SARMIENTO, Domingo Faustino (1954). Correspondencia entre Sarmiento y Lastarria (1849-1888). Buenos Aires: Artes Gráficas Bartolomé U. Chiesino. 
(1900). Conflictos y armonías de las razas en América. Buenos Aires: Editorial La Cultura.

[1845] (1990). Facundo. Civilización y Barbarie. Madrid: Cátedra.

SCENNA, Miguel Ángel (1976). Los que escribieron nuestra historia. Buenos Aires: Editorial Astrea.

SOISA REILLY, Juan José (1905). "Gente de color". Caras y Caretas, 25 de noviembre.

SOLER CAÑAS, Luis (1967). "Gabino Ezeiza". Todo es Historia, no 2, pp. 64-77. SOLOMIANSKI, Alejandro (2003). Identidades secretas: la negritud argentina. Buenos Aires: Beatriz Viterbo Editora.

TERÁN, Oscar (2008). Vida intelectual en el Buenos Aires fin-de-siglo (1880-1910): Derivas de la cultura cientifica. Buenos Aires: Fondo de Cultura Económica.

YAO, Jean-Arsène (2004). "El poder de la prensa, la prensa del poder: reflexión entorno al periodismo afroargentino". Amnis, nº, pp. 243-253.

\section{Notas}

1 En La Igualdad por ejemplo se anunciaba la "Línea Mensual de Vapores Italianos entre Génova y Río de la Plata de Lavarello y Cia".

2 En 17 de enero de 1880, La Broma se hacía eco de la restricción de la entrada de "personas de color" a algunos salones de baile, lo que obligó a la intervención del diputado Héctor Varela. "Dos de los establecimientos públicos en que se dan bailes de máscaras, han prohibido la entrada a las gentes de color, más claro: a los negros y mulatos. ¿Lo sabe la Policía? ¿Tiene conocimiento de esta prohibición? Debemos suponer que no, porque de otro modo, no habría consentido que un empresario de bailes de máscaras, cometiese un atentado tan grande a la Constitución, que establece la igualdad de todos los argentinos sin distinción de colores, y a los principios democráticos que nos rigen, y que practicamos con la verdad de hombres libres y no con hipocresía".

3 Ejemplo de ello son el libro "Tinta negra en el gris del ayer. Los afroporteños a través de sus periódicos entre 1873 y 1882", publicado en 2009 por Norberto Pablo Cirio; los artículos "Guardianes del progreso. Los periódicos afroporteños entre 1973-1882” y “Aquí... se habla de política. La participación de los afroporteños en las elecciones presidenciales de 1874", publicados por Lea Geler, respectivamente en el Anuario de Estudios Americanos, 65 (2008) y Revista de Indias, 240 (2007); "El poder de la prensa, la prensa del poder: reflexión en torno al periodismo afroargentino", de Jean-Arsène Yao, en la revista Amnis, de la universidad de Brest (2004).

4 Partidarios del poder central de Buenos Aires, del que dependerían las demás provincias.

5 Partidarios de las autonomías provinciales, cuya figura destacada fue el gobernador de Buenos Aires Juan Manuel de Rosas.

6 Durante la época del Gobernador Rosas (1829-1832 y 1834-1852), el Candombe resurgió, logrando vivir su periodo de mayor apogeo. El mismo gobernador asistía en compañía de su hija Manuelita a las festividades de los negros en las que era habitual que éstos le hicieran honores. Durante su gobierno se levantaron las prohibiciones a los candombes impuestas en 1820 y 1838 y justo en ese último año el gobernador invitó a la comunidad de las naciones negras a bailar en la plaza central (actual Plaza de mayo) para celebrar el día de la independencia.15 El baile de negros en la celebración del 25 de mayo de 1838 desató la ira de los miembros de la élite y fue visto como un desagravio a la celebración nacional. Los negros manifestaron su disposición para servir a los ejércitos de Rosas, 
además se exhibían las insignias rojas federales, desfilando por las calles después de cada victoria federal.

7 La generosidad de Rosas encubría la explotación de los negros para fines políticos, ya que puso en marcha una práctica de espionaje en la cual los negros eran encargados de delatar a sus amos unitarios y hacerlos el blanco de la persecución. Por esto el apoyo de la comunidad negra a Rosas nunca fue unánime. El coronel negro José María Morales era unitario. Y no faltaron quienes organizaron complots contra él, como fue el caso del mulato Carranza o los que se pasaron de un bando a otro como el coronel Lorenzo Barcala.

8 La clase dirigente que acompaña el proceso de modernización en el que el progreso económico y la organización política provocan el surgimiento de una nueva sociedad, a partir de 1880, es la denominada Generación del ' 80 . En ella se destacan personalidades de distinta edad y formación como Paul Groussac, Miguel Cané, Eduardo Wilde, Carlos Pellegrini, Luis Sáenz Peña y Joaquín V. González. Tuvieron una visión positivista marcada por la idea de progreso en el campo social junto a la fe en los avances del capitalismo industrial, que generaron una visión optimista del futuro humano.

9 El carnaval se opuso a la racionalidad que buscaba el control y el dominio de sí, la legitimación de una sola lógica de poder, la fijación de fronteras étnicas, morales, la imposición de gustos y modales, (Romeo, 2005). A cambio de esto posicionó en su festejo el descontrol, la fractura en límites morales, étnicos, el quiebre temporal de clasificaciones, la desmesura, la risa, la mezcla de etnias, clases, géneros subvirtiendo muchas de las normas que sofocaban la vida ordinaria de la gente (Ocoró, 2010: 53). 